\title{
AUTHOR INDEX FOR VOLUME 98
}

BALLESTER-BOLINCHES, A.; see SU, N. 109

BOWDEN, R. S.; Modelling joint autoregressive moving average processes $\quad 345$

BROUGH, J. and KONG, Q.; On vanishing criteria that control finite group structure II

BUGAJEWSKI, D. and MAĆKOWIAK, P.; Continuity of roots, revisited 448

BUGEAUD, Y. and KEKEÇ, G.; On Mahler's classification of $p$-adic numbers 203

CAREVIĆ, M. M.; see PANIĆ, S. 331

CHAMBERLAIN, R.; Minimal exceptional $p$-groups $\quad 434$

CHAPMAN, A.; Common slots of bilinear and quadratic Pfister forms 38

CHENG, S.-Q.; Doubling tropical $q$-difference analogue of the lemma on the logarithmic derivative

CHOI, B. J.; Convergence of Mann's alternating projections in CAT $(\kappa)$ spaces $\quad 134$

DE BONDT, M. and SUN, X.; Classification of cubic homogeneous polynomial maps with Jacobian matrices of rank two

DENG, M.-J., GUO, J. and XU, A.-J.; A note on the Diophantine equation $x^{2}+(2 c-1)^{m}=c^{n}$

DJANKOVIĆ, G.; The reciprocity law for the twisted second moment of Dirichlet $L$-functions over rational function fields

DRAGOMIR, S. S.; Weighted integral inequalities of Ostrowski, Čebyšev and Lupaş type with applications

DUBICKAS, A.; Algebraic numbers with bounded degree and Weil height

DUNG, N. V. and HANG, V. T. L.; On the completion of $b$-metric spaces

FAULHUBER, M.; A short note on the frame set of odd functions

GAÁL, M. and NAGY, G.; Transformations on density operators preserving generalised entropy of a convex combination

GABELEH, M. and VETRO, C.; A new extension of Darbo's fixed point theorem using relatively Meir-Keeler condensing operators

GOLDFARB, B. and GROSSMAN, J. L.; Coarse coherence of metric spaces and groups and its permanence properties

GROSSMAN, J. L.; see GOLDFARB, B.

GUAN, Y; see SHI, M.

GUO, J.; see DENG, M.-J.

GÜRER, S. and IGLESIAS-ZEMMOUR, P.; Differential forms on stratified spaces

HALL, T.; see YURTTAŞ, S. Ö.

HANG, V. T. L.; see DUNG, N. V.

HE, H.; Input-output analysis of relationships between the Australian economic system and waste management

HERNÁNDEZ, E. and PIERRI, M.; $\mathcal{S}$-asymptotically periodic solutions for abstract equations with state-dependent delay 
HIRATA, K.; Two-sided estimates for positive solutions of superlinear elliptic boundary value problems

HSU, D. F. and ZHOU, S.; Resolvable Mendelsohn designs and finite Frobenius groups

HUA, H.; On the total distance and diameter of graphs

HUANG, Z.; Mathematical analysis of combustion waves in competitive exothermic reactions

HUSSAIN, N., YAU, S. S.-T. and ZUO, H.; On the derivation Lie algebras of fewnomial singularities

IGLESIAS-ZEMMOUR, P.; see GÜRER, S.

KEKEÇ, G.; see BUGEAUD, Y.

KHANMOHAMMADI, E.; A structured inverse spectrum problem for infinite graphs and unbounded operators

KLAVŽAR, S.; see MANUEL, P.

KOMURO, N., SAITO, K.-S. and TANAKA, R.; Left symmetric points for Birkhoff orthogonality in the preduals of von Neumann algebras

KONG, Q.; see BROUGH, J.

KONG, Q.-G., RUAN, H.-J. and ZHANG, S.; Box dimension of bilinear fractal interpolation surfaces

KWOK, E.; Dynamic isoperimetry on graphs and weighted Riemannian manifolds

LEE, J.; A note on Gunningham's formula

LI, F.; On systems of partial differential equations of Briot-Bouquet type

LI, F., LI, Q. and LIU, Y.; A reaction-diffusion-advection equation with combustion nonlinearity on the half-line

LI, Q; ; see LI, F.

LI, Y.; Exploring the role of small-scale thermohaline structure on mixing and transport in the ocean

LIU, J.-C.; Supercongruences involving $p$-adic gamma functions

LIU, Y.; see LI, F.

LONGSTAFF, W. E.; On minimal sets of $(0,1)$-matrices whose pairwise products form a basis for $M_{n}(\mathbb{F})$

MAINZER, R.; The effect of a preliminary Hausman test on confidence intervals 518 MANUEL, P. and KLAVŽAR, S.; A general position problem in graph theory

MARQUES, D. and MOREIRA, C. G.; A note on a complete solution of a problem posed by K. Mahler

MCDOUGALL, R. G. and THORNTON, L. K.; On base radical operators for classes of finite associative rings

MEAGHER, S.; A simple proof of Chebotarev's density theorem over finite fields 
MORARIU-PATRICHI, M.; On the weak-hash metric for boundedly finite integer-valued measures

MOREIRA, C. G.; see MARQUES, D. $\quad 60$

NAGY, G.; see GAÁL, M. 102

ONARAN, S.; On overtwisted contact surgeries $\quad 144$

ORTEGA-PIWONKA, I.; Stochastic models for optically trapped nanowires 343

PANIĆ, S., PETROVIĆ, M. J. and CAREVIĆ, M. M.; Initial improvement of the hybrid accelerated gradient descent process

PATRA, A. and SRIVASTAVA, P. D.; Relative perturbation bounds for the joint spectrum of commuting tuples of matrices

PETROVIĆ, M. J.; see PANIĆ, S.

PIERRI, M.; see HERNÁNDEZ, E.

POOR, C., SHURMAN, J. and YUEN, D. S.; Theta block Fourier expansions, Borcherds products and a sequence of Newman and Shanks

RUAN, H.-J.; see KONG, Q.-G.

ŞAHIN, M.; Liftings of a monomial curve

SAITO, K.-S.; see KOMURO, N.

SANKI, B.; Systolic fillings of surfaces

SAUNDERS, J. C.; Mahler measure of 'almost' reciprocal polynomials

SHI, M., GUAN, Y., WANG, C. and SOLÉ, P.; Few-weight codes from trace codes over $R_{k}$

SHI, M.; see ZHU, H. W.

SHURMAN, J.; see POOR, C.

SITTINGER, B. D.; The density of $j$-wise relatively $r$-prime algebraic integers

SOLÉ, P.; see SHI, M.

SONENBERG, N.; Networks of interacting stochastic fluid models 516

SPRATT, B.; Reactive operating theatre scheduling

SRICHAN, T.; On the absence of zeros in infinite arithmetic progression for certain zeta functions

SRIVASTAVA, P. D.; see PATRA, A.

STA $\breve{S}, M$; Determining crossing numbers of graphs of order six using cyclic permutations

SU, N., BALLESTER-BOLINCHES, A. and MENG, H.; A note on normal complements for finite groups

SUN, X.; see DE BONDT, M.

TANAKA, R.; see KOMURO, N.

TANNA, D. K.; Graph labelling techniques

TERAGAITO, M.; Weight elements of the knot groups of some three-strand pretzel knots

THORNTON, L. K.; see MCDOUGALL, R. G. 239

VETRO, C.; see GABELEH, M. 286

WANG, C.; see SHI, M. 
WHYTE, J. M.; Global a priori identifiability of models of flow-cell optical biosensor experiments

XU, A.-J.; see DENG, M.-J.

YAU, K. H.; Bounds for triple exponential sums with mixed exponential and linear terms

YAU, S. S.-T.; see HUSSAIN, N.

YUEN, D. S.; see POOR, C.

YURTTAŞ, S. Ö. and HALL, T.; Intersections of multicurves from Dynnikov coordinates

ZHANG, P. B.; The local $h$-polynomials of cluster subdivisions have only real zeros

ZHANG, S.; see KONG, Q.-G.

ZHONG, L.; The complexity of Thomason's algorithm for finding a second Hamiltonian cycle

ZHOU, S.; see HSU, D. F.

ZHU, H. W. and SHI, M.; On linear complementary dual four circulant codes

ZUDILIN, W.; Some hypergeometric integrals for linear forms in zeta values 


\section{INFORMATION FOR AUTHORS}

The Bulletin of the Australian Mathematical Society aims at quick publication of original research in all branches of mathematics. To ensure speedy publication, only articles which are sufficiently well presented, able to be published without revision, and which are judged by the Editor (often in consultation with an Associate Editor) to be competitive are refereed. This policy is in the interests of authors, as a quick rejection is better than a slow rejection. The Bulletin receives more than five times the material that can be published, therefore there are many commendable papers not accepted. Editorial decisions on acceptance or otherwise are taken quickly, normally within a month of receipt of the paper. Papers are accepted only after peer review.

Manuscripts are accepted for review with the understanding that the same work is not concurrently submitted elsewhere. For a paper to be acceptable for publication, not only should it contain new and interesting results, but also

(i) the exposition should be clear and attractive, and

(ii) the manuscript should be in publishable form, without revision.

Further information regarding these requirements may be found through our website www.austms.org.au/Bulletin. Authors are asked to avoid, as far as possible, the use of mathematical symbols in the title.

Articles should be prepared in $\mathrm{ET}_{\mathrm{E}} \mathrm{X}$ using $\mathcal{A}_{\mathcal{M}} \mathcal{S}$-LTEX packages and submitted as a PDF file via our journal management system, at www.austms.org.au/Publications/Submissions/BAustMS. This permits authors to track their papers through the editorial process. Recent versions of $\mathrm{T}_{\mathrm{E}} \mathrm{X}$ are able to produce PDF files directly. A LTTEX class file for the Bulletin can be downloaded from the website. Authors who need assistance may email the secretary of the Bulletin at editor@bulletin.austms.org.au.

Authors are advised to keep copies of all files of the submitted article; the Bulletin will not accept responsibility for any loss.

\section{EDITORIAL POLICY}

1. References. Arrange references alphabetically (by surname of the first author) and cite them numerically in the text. Ensure the accuracy of the references: authors' names should appear as in the work quoted. Include in the list of references only those works cited, and avoid citing works which are in preparation or submitted. Where the work cited is not readily accessible (for example, a preprint) a copy of the article should be included with your submission.

\section{Abstracts.}

1. Each paper must include an abstract of not more than 150 words, which should contain a brief but informative summary of the contents of the paper, but no inessential details.

2. The abstract should be self-contained, but may refer to the title.

3. Specific references (by number) to a section, proposition, equation or bibliographical item should be avoided.

3. Subject Classification and Key Words. Authors should include a few key words and phrases and one or more classification numbers, following the American Mathematical Society 2010 Mathematics Subject Classification for all codes. Details of this scheme can be found on the web at www.ams.org/msc.

4. Abstracts of PhD Theses. The Bulletin endeavours to publish abstracts of all accepted Australasian $\mathrm{PhD}$ theses in mathematics. One restriction, however, is that the abstract must be received by the Editor within six months of the degree being approved.

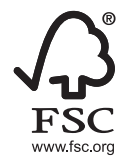

This journal issue has been printed on FSC-certified paper and cover board. FSC is an independent, non-governmental, not-for-profit organisation established to promote the responsible management of the world's forests. Please see www.fsc.org for information. 


\section{Table of Contents}

Determining crossing numbers of graphs of order six using cyclic permutations

Stas, $M$.

A structured inverse spectrum problem for infinite graphs and unbounded operators

Khanmohammadi, E.

Some hypergeometric integrals for linear forms in zeta values

Zudilin, $W$.

On the absence of zeros in infinite arithmetic progression for certain zeta functions

Srichan, $T$.

The reciprocity law for the twisted second moment of Dirichlet $L$-functions over rational function fields

Djanković, $G$.

A note on Gunningham's formula

Lee, 7 .

On minimal sets of $(0,1)$-matrices whose pairwise products form a basis for $M_{n}(\mathbb{F})$

Longstaff, W. E.

Relative perturbation bounds for the joint spectrum of commuting tuples of matrices

Patra, A. \& Srivastava, P. D.

Coarse coherence of metric spaces and groups and its permanence properties

Goldfarb, B. \& Grossman, 7. L.

Minimal exceptional $p$-groups

Chamberlain, $R$.

Weighted integral inequalities of Ostrowski, Čebyšev and Lupaş type with applications

Dragomir, S. S.

Continuity of roots, revisited

Bugajewski, D. \& Maćkowiak, $P$.

$\mathcal{S}$-asymptotically periodic solutions for abstract equations with state-dependent delay

Hernández, E. \& Pierri, $M$.

Two-sided estimates for positive solutions of superlinear elliptic boundary value problems

Hirata, $K$.

Doubling tropical $q$-difference analogue of the lemma on the logarithmic derivative

Cheng, S.-Q.

A short note on the frame set of odd functions

Faulhuber, $M$

Left symmetric points for Birkhoff orthogonality in the preduals of von Neumann algebras

Komuro, N., Saito, K.-S. \& Tanaka, R.

Systolic fillings of surfaces

Sanki, $B$.

Abstracts of PhD Theses

Graph labelling techniques

Tanna, D. K.

Dynamic isoperimetry on graphs and weighted Riemannian manifolds

Kwok, E.

Networks of interacting stochastic fluid models

Sonenberg, $\mathcal{N}$.

The effect of a preliminary Hausman test on confidence intervals

Mainzer, $R$.

Reactive operating theatre scheduling

Spratt, $B$.

Input-output analysis of relationships between the Australian economic system and waste management $\mathrm{He}, \mathrm{H}$. 